\title{
Análise das Repercussões do Ambulatório de Saúde Indígena nos Processos de Formação Acadêmica na UnB: Olhares Indígenas
}

\author{
Rayanne Cristine Máximo França \\ Universidade de Brasília - UnB \\ e-mail: rayannecrist@gmail.com
}

Palavras-chave: saúde indígena, formação em saúde, interculturalidade.

Com a ascensão das políticas de ações afirmativas nas universidades públicas, a inclusão dos povos indígenas no ensino superior ainda representa um fenômeno recente e, como tal, estão em construção os mecanismos de trocas e intercâmbios de saberes necessários para sua melhoria. Nesse contexto, destaca-se a importância do processo histórico de criação do Ambulatório de Saúde Indígena (ASI) do Hospital Universitário de Brasília (HUB), cuja construção e implementação contou com a participação integral dos estudantes indígenas de distintos cursos da Universidade de Brasília (UnB). Essa dinâmica levou em conta a premência de avançar nos processos de mudança do modelo de formação rumo a novas práticas que avancem no sentido da interculturalidade. Para tanto, foi desenvolvida esta pesquisa que visou analisar as repercussões ASI-HUB na formação acadêmica dos estudantes indígenas.

A pesquisa participante, de abordagem qualitativa, teve como sujeitos da pesquisa os estudantes indígenas da UnB. O critério de inclusão foi a participação pregressa no Ambulatório de Saúde Indígena, entre 2013 e 2015. $O$ instrumento de pesquisa adotado foi entrevista semiestruturada. A coleta dos dados foi realizada através de 05 entrevistas individuais, segmentadas pelos diferentes cursos de graduação: medicina, enfermagem, nutrição, agronomia e engenharia florestal. $O$ critério de inclusão desses cursos teve como base àqueles que congregam maior quantidade de estudantes indígenas e que participaram do Programa de Educação Tutorial (PET) Saúde Indígena no ASI-HUB no período mencionado. Os dados foram analisados a partir da Análise de Conteúdo de Bardin (1977), a qual conduziu à quatro categorias. 
A categoria "Repercussões gerais da experiência do ASI" evidencia que os entrevistados caracterizam esta experiência como um processo de demarcação da presença indígena dentro da universidade. A categoria "Repercussões institucionais da experiência do ASI no que tange às práticas de atenção à saúde dos povos indígenas", destaca que a abertura política da Faculdade de Saúde e do Departamento de Saúde Coletiva foram essenciais para a criação do ASI. A categoria "Repercussões da experiência do ASI no que tange às práticas de atenção à saúde dos povos indígenas", revela a conviç̧ão dos estudantes indígenas no que se refere às mudanças no âmbito do HUB. A categoria "Repercussões da experiência do ASI no que tange à construção da interculturalidade", evoca que a experiência gerou mudanças intra e extramuros, visto que alguns atores da UnB passaram a enxergar os povos indígenas como sujeitos de direitos.

Ressalta-se que em todas as entrevistas o ASI é visto como uma experiência positiva, que permitiu entender melhor o sistema de saúde e refletir sobre a melhoria de seus serviços, a partir da diversidade de olhares e da compreensão das questões étnicas, culturais e sociais. Entende-se que é necessário o fortalecimento do ASI-HUB, pois este tipo de experiência permitiu avançar na compreensão da importância da mudança do modelo de formação universitária e, consequentemente, ter profissionais capazes de lidar com a temática indígena em qualquer espaço, favorecendo a sensibilização profissional quanto à importância da interculturalidade e a melhoria da qualidade de atenção à saúde dos povos indígenas. 